\title{
Results of radon CR-39 detectors exposed in schools due two different long-term periods
}

\author{
Zdenka Stojanovska, \\ Blazo Boev, \\ Zora S. Zunic, \\ Peter Bossew, \\ Svetlana Jovevska
}

\begin{abstract}
The paper deals with the recent survey of indoor radon (Rn) results in schools, where paired CR-39 detectors were simultaneously exposed to different long-term periods, i.e., one detector was exposed during the whole year and the other one in the period of the school year duration. To be able to compare the results obtained, for its analysis, the relative bias and $U$ tests were used. It was found that there are no systematic differences between the results, which points that the exposure of the detector during summer vacations did not affect the estimated average annual radon concentration. The paired results were modelled by a linear function, giving an extremely high coefficient of determination $R^{2}=0.99$.
\end{abstract}

Key words: comparison $\bullet$ linear regression analysis $\bullet$ relative bias $\bullet$ U test

Z. Stojanovska ${ }^{\bowtie}$, S. Jovevska

Faculty of Medical Sciences,

Goce Delcev University,

Krste Misirkov No. 10-A, P. O. 201, Stip-2000,

Republic of Macedonia,

Tel.: +38932550 400,

E-mail: zdenka.stojanovska@ugd.edu.mk

B. Boev

Faculty of Natural and Technical Sciences,

Goce Delcev University,

Krste Misirkov No. 10-A, P. O. 201, Stip-2000,

Republic of Macedonia

\section{Z. S. Zunic}

University of Belgrade,

Vinča Institute of Nuclear Sciences,

P. O. Box 522, 11000 Belgrade, Serbia

\section{P. Bossew}

German Federal Office for Radiation Protection, div. SW 1.1,

120-130 Köpenicker Allee, D-10318 Berlin, Germany

Received: 23 December 2015

Accepted: 24 March 2016

\section{Introduction}

Worldwide scientific studies have shown that indoor radon $(\mathrm{Rn})$ is the main source of radiation exposure for the general population throughout the world [1]. Taking into account the health effects of $\mathrm{Rn}$ and its large-scale geographical and temporal variability, investigation of their concentrations in the living and working environments still affords scientific attention.

Different methods to determine Rn exposure of the population as accurately as possible have been developed. Measuring techniques, in general, include active and passive methods, providing short- and long-term measurements. Depending on the purpose of measurement, different technique is applied. If preliminary assessment is required of whether the concentration is high or low, active and passive short-term measurements give satisfactory results. Considering the strong daily, monthly, and seasonal variation of the $\mathrm{Rn}$, long-term techniques are more appropriate, if more accurate and precise determination of the long-term mean is required. From the radiation protection point of view, the limits are based on the annual average concentrations. Therefore, one-year measurements give more reliable results. On the other hand, such long-term measurements have certain negative consequences: one has to wait for a long time for a result; people do not always enthusiastically accept the fact that keeping the detector for an entire year in their indoor environment is necessary, and very often are likely to lose the detector. 
To overcome this situation, Rn practitioners make efforts to achieve reasonably accurate estimates from shorter time exposure. There are essentially two ways to achieve this: (1) expose the detectors during a time of the year, which probably covers most of the temporal variability, i.e. usually in spring or autumn; (2) establish a mathematical model of dependence between short- and long-term measurements results obtained by the same and/or different Rn measurement techniques in certain real conditions. Usually, as a measure of relation, the Pearson correlation coefficient is used. Moreover applying a mathematical regression model, the annual Rn concentration can be estimated from short-term measurements [2].

When choosing an appropriate exposure period, one may consider usage and occupancy patterns of a building, because this is a factor known to have an impact on the Rn levels. For example, schools are not occupied during vacations, and one may argue that $\mathrm{Rn}$ levels during that period are irrelevant. In Macedonia, for example, the longest period during the year when schools are closed, is summer vacations, which last 3 months starting from June to September. In this period, the building is fully closed or maintenance or renovation works are performed. In any case, one can assume that this period does not match the actual conditions during the school year. Inspired by this idea, we performed a small experiment in primary schools of three municipalities, exposing simultaneously two detectors with different periods of exposure, one for the whole year and one of nine months (i.e., except summer vacations). This paper presents the results of that work.

\section{Materials and methods}

The survey was conducted in all primary schools of three municipalities in Macedonia (Fig. 1).

The measurements were made with nuclear track detectors, commercially named Gamma 1, which were provided and analysed by Landauer Company, Sweden. They consist of a CR-39 detecting material placed on the bottom of a cylindrical diffusion chamber dimensions $\varnothing 58 \mathrm{~mm} \times 20 \mathrm{~mm}$. The esti-

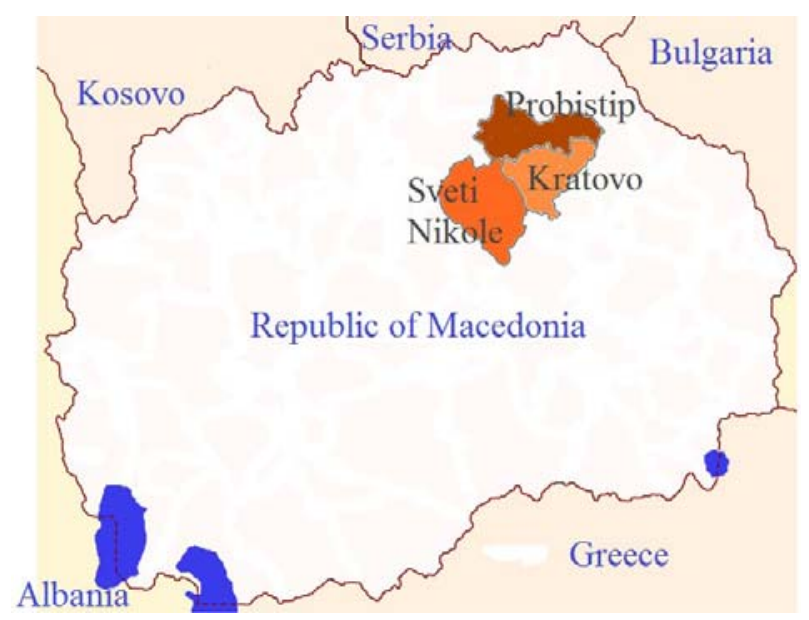

Fig. 1. Schematics of the geographic positions of the three municipalities where the survey has been performed.
Table 1. Descriptive statistic of the measured Rn concentrations in 12 and 9 months periods

\begin{tabular}{lcc}
\hline \multicolumn{1}{c}{ Statistic } & $\begin{array}{c}\mathrm{Rn}(12) \\
{\left[\mathrm{Bq} / \mathrm{m}^{3}\right]}\end{array}$ & $\begin{array}{c}\mathrm{Rn}(9) \\
{\left[\mathrm{Bq} / \mathrm{m}^{3}\right]}\end{array}$ \\
\hline No. of observations & 29 & 29 \\
Minimum & 22 & 24 \\
Maximum & 990 & 962 \\
Median & 115 & 109 \\
Arithmetic mean & 215 & 211 \\
Standard deviation & 246 & 236 \\
Coefficient of variation [\%] & 115 & 112 \\
Geometric mean & 129 & 128 \\
Geometric standard deviation & 2.76 & 2.72 \\
\hline
\end{tabular}

mated values of the relative combined uncertainty of individual results in this study, which include uncertainties of track counting, time, calibration factor, and the detector background, were in the range 11 to $19 \%$. This type of detector is also used in other scientific research [3, 4].

In all 31 schools, in a classroom on the ground floor, paired Gamma 1 detectors were deployed on the wall. The first detector was exposed during the whole year, from September 2013 to August 2014, and the second one in the period of the school year duration, starting September 2013 to May 2014 only. During the campaign, two detectors were lost; thus, we analysed 29 paired results at the end.

\section{Results}

In Table 1, the descriptive statistic of Rn concentrations measured with detectors exposure 12 months $\left(C_{\mathrm{Rn}}(12)\right)$ and 9 months $\left(C_{\mathrm{Rn}}(9)\right)$ are presented.

The arithmetic and geometric mean values are almost the same between the detectors exposed in different periods. The same applies for dispersion of the results. In both cases, the coefficient of variation and geometric standard deviation have high values. The reasons for dispersions between schools are the variability of the factors that controls indoor $\mathrm{Rn}$, namely the geogenic $\mathrm{Rn}$ potential (different geological base) and building characteristics in terms of Rn infiltration and accumulation [4]. Furthermore, the results from both detectors have about the same distribution (Fig. 2).

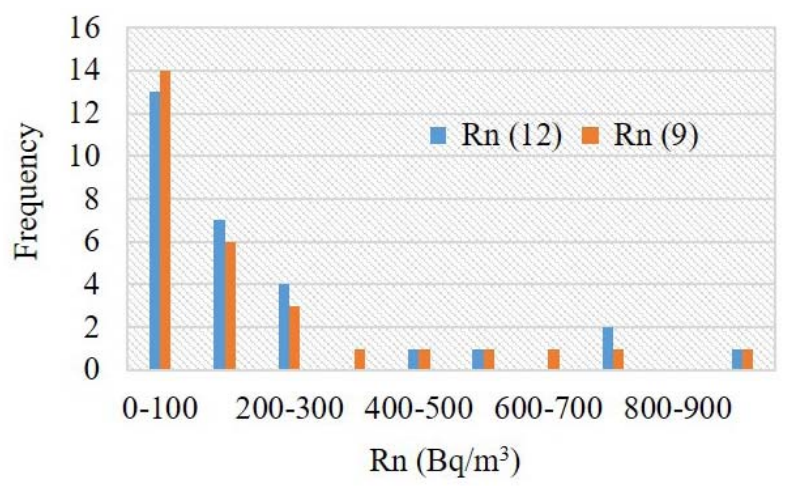

Fig. 2. Histograms of the results of detectors exposed 12 and 9 months. 
In order to quantify the difference between the paired measurements of the $R n(12)$ and $R n(9)$ concentrations, the relative bias was used. Its value was estimated using the definition given in Eq. (1).

$$
\mathrm{B}=\frac{\operatorname{Rn}(12)-\operatorname{Rn}(9)}{\operatorname{Rn}(9)} \cdot 100 \%
$$

The results expressed in percentage, together with paired $\mathrm{Rn}(12)$ and $\mathrm{Rn}(9)$, are plotted in Fig. 3. The range of $\mathrm{B}$ was found to be from $-30 \%$ to $31 \%$. In five (of 29) cases related to the $\mathrm{Rn}$ concentrations $<100 \mathrm{~Bq} / \mathrm{m}^{3}$, the $|\mathrm{B}|$ was higher than $20 \%$. Such high bias is usually considered as not acceptable for passive radon instruments [5]. A correlation between $\mathrm{Rn}$ and bias was not confirmed.

Further, for comparison, the measured results of the two detectors including its uncertainty $(u)$, the $\mathrm{U}$ test was applied. Its test statistic is defined in Eq. (2).

$$
\mathrm{U}=\frac{|\operatorname{Rn}(12)-\operatorname{Rn}(9)|}{\sqrt{u^{2}(\operatorname{Rn}(12))-u^{2}(\operatorname{Rn}(9))}}
$$

The plotted results are presented in Fig. 3. The $\mathrm{U}$ values were in the range from 0.06 to 2.06 , where ranges for $\mathrm{Rn}$ concentrations $<100 \mathrm{~Bq} / \mathrm{m}^{3}$ and $>100 \mathrm{~Bq} / \mathrm{m}^{3}$ were from 0.06 to 2.06 and 0.07 to 0.99 , respectively. It is obvious that high values of $U$ are connected with low values of the Rn concentration and vice versa.

The obtained $U$ value was compared with the critical value listed in the $t$ - statistic tables to determine if the reported results differ significantly from each other at a given level of confidence. In our experiment, 28 results satisfy the criterion: $\mathrm{U}<1.65$. It means that these results are not different at $95 \%$ levels of probability.
Even if the mean bias was not significant, we further tested the possibility of $\mathrm{Rn}(9)$ to be lower or higher than $\mathrm{Rn}(12)$. For each data pair $(\mathrm{Rn}(9)$, $\mathrm{Rn}(12)$ ), the difference (or the difference of the logarithms) was calculated and the resulting set of differences tested against the hypothesis difference $=0$. Here again, the $t$-test and two non-parametrical tests (sign and signed rank test) indicate no significant difference to zero, neither for the original nor for the $\ln$ transformed values.

The results suggest to conclude that variance in the measured results is only caused by the statistical fluctuations related to the Rn measurement and by the period of detector exposure. In the scientific literature, different results from comparisons of the Rn concentrations obtained mainly from short- and long-term measurements can be found. The differences are more pronounced between short-term measurement by active method and passive long-term method. For example, using short-term measurements with active method, Clouvas et al., 2009 found that: (a) in school with a high level of radon during school time, the concentrations were lower by a factor of 7 than when the school was closed; (b) in school with low levels, this difference was a factor of 4 [6]. Similar radon dynamic has been reported for Slovenian schools $[7,8]$. Smaller differences were obtained from the measurements in 36 kindergartens and 44 schools in Upper Austria, using active and passive short- and long-term passive measurements. They reported ratios radon concentrations working hours/total average of 0.9 for kindergartens and 1.2 for schools with variation between 0.27 and 3.72 [9]. On the other hand, research conducted in 25 houses in Kosovo, where measurements were made with passive detectors exposed in two suc-
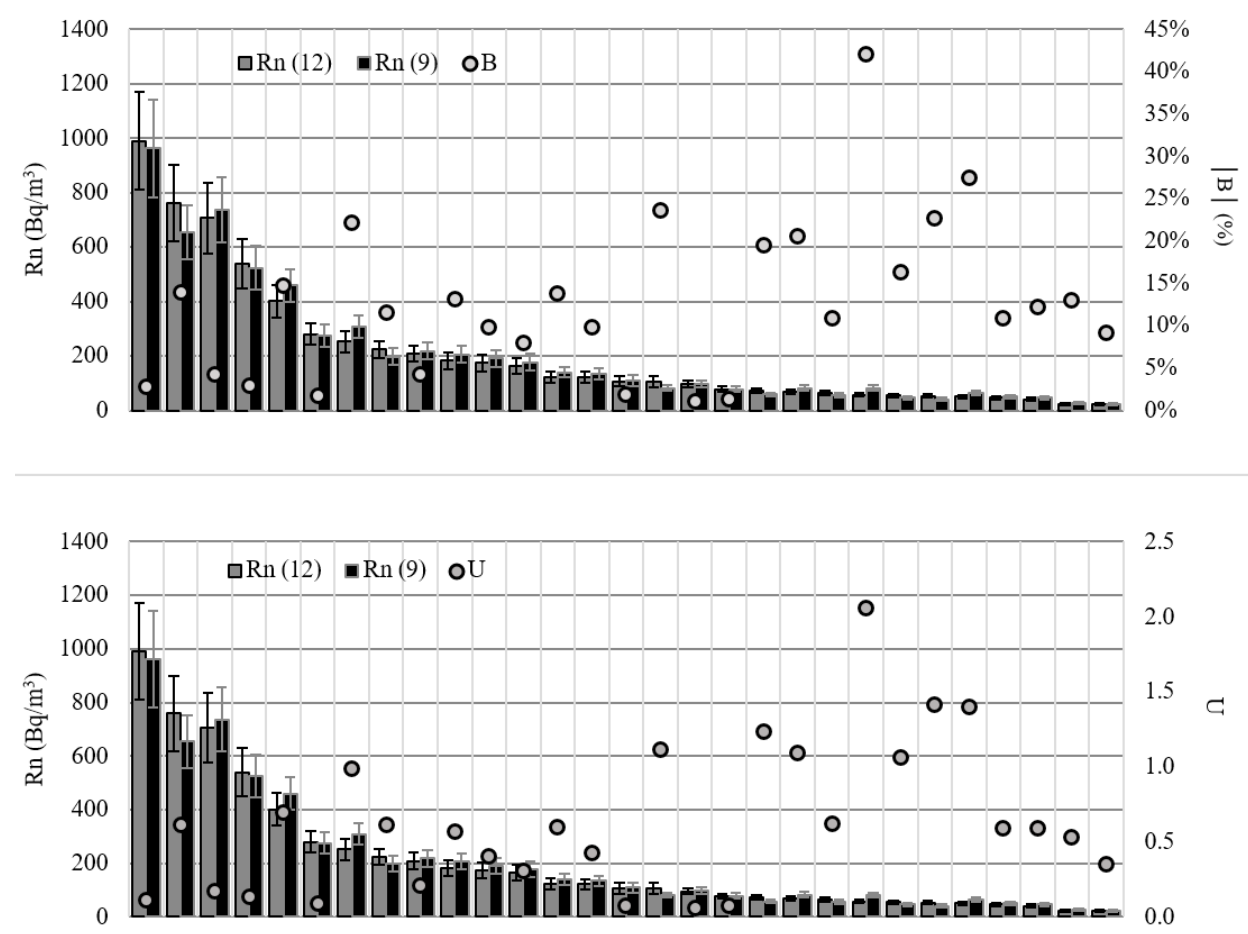

Fig. 3. Results of detectors exposed for 12 and 9 months together with a corresponding bias (upper graph) and parameter of $U$ test (lower graph). The error bars indicate the uncertainty of the measured concentrations. 


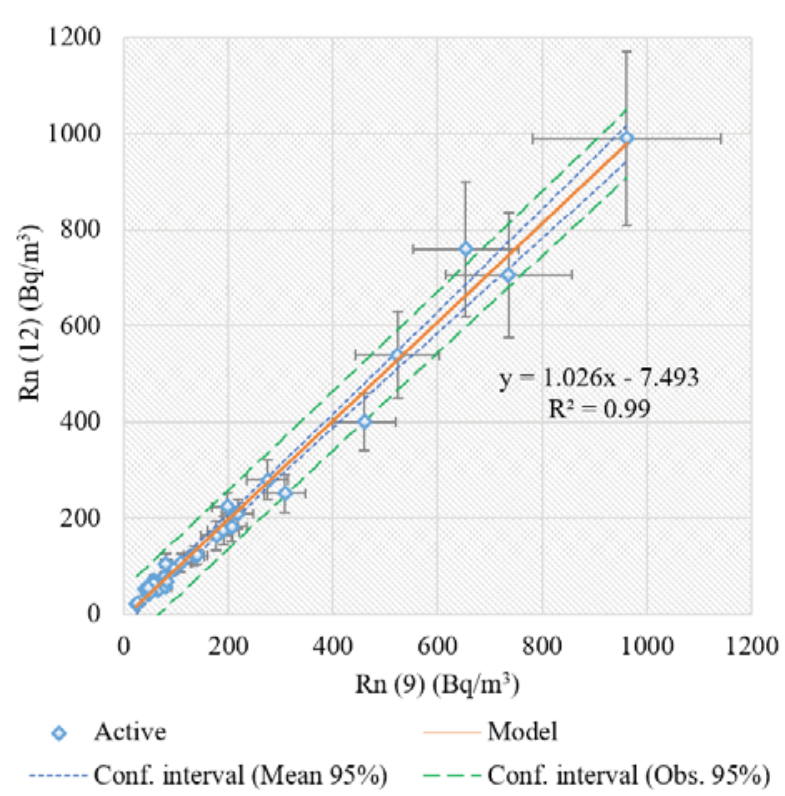

Fig. 4. Linear regression model of paired $\mathrm{Rn}(12)$ and $\mathrm{Rn}(9)$ concentrations. The error bars indicate uncertainty of the measured concentrations.

cessive periods of 6 months, showed no difference in the measured concentrations [10].

The next step in data analysis was to establish a mathematical model that explained the relationship between the paired concentrations. The linear model of the regression analysis of $\mathrm{Rn}(12)$ and $\mathrm{Rn}(9)$ is shown in Fig. 4. A strong association between the two sets of values is recognized due to high Pearson coefficient of determination $\left(R^{2}=0.99\right)$. The slope is close to 1 , which shows the absence of bias.

For comparison, the coefficient of determination of the modelled short-term (active method) and long-term (6 months) radon measurements in Saudi Arabia was low with a value of $R^{2}=0.38$ [11]. A stronger correlation of $R^{2}=0.67$ was obtained in measurements in Bulgarian schools and kindergartens using passive short- (exposed due summer vacation) and long-term (8 months) measurements [12]. A similar value of $R^{2}=0.76$ is reported for the relation between short-term (exposed in winter) and long-term (annual exposure) measurements in basements of radon-prone area [13].

The results shown in this study came somewhat unexpected. Normally, during holidays, when school buildings are closed, and therefore, less ventilated, the Rn concentrations tend to build up. One would, therefore, expect higher $\mathrm{Rn}(12)$ than $\mathrm{Rn}(9)$ values. On the other hand, there is an annual cycle in the $\mathrm{Rn}$ infiltration rate, which is lower in summer than in winter by factor 4 [14]. Therefore, it may be that these effects compensate to a good extent.

In spite of the very clear result of equal mean Rn concentration, summer vacations included or not, one should be cautious before generalizing it. The result is based on a relatively small sample that comes from a particular geographic region. For further research, we suggest to investigate whether there is an influence of the climatic conditions (to which geographical location is related).

\section{Conclusion}

A small experiment including 29 schools within three municipalities was performed. In each school, paired CR-39 detectors were exposed side-by-side in different periods, that is, 12 and 9 months, respectively, starting their deployment both from September 2013 year.

In spite of the large variations between the $\mathrm{Rn}$ concentrations measured in different schools, no influence of different exposure time could be identified.

Differences between $\mathrm{Rn}(12)$ and $\mathrm{Rn}(9)$ were analysed by the relative bias and $U$ test. It was found that dissimilarities in the measured values were not significant, and that they originated from the fluctuation of Rn due to measurement statistics.

The dependence of the $\mathrm{Rn}(12)$ and $\mathrm{Rn}(9)$ was modelled with a linear function with a high coefficient of determination.

Acknowledgments. The authors would like to express their gratitude to the schools directors and mayors of Sveti Nikole, Kratovo, and Probistip municipalities for collaboration during this survey. This survey was funded by the research fund of the Goce Delcev University, Stip, Republic of Macedonia. The Gamma 1 detectors were provided by the scientific collaboration and support within the Project P-41028 of the Ministry of Education, Science and Technological Development of the Republic of Serbia.

\section{References}

1. UNSCEAR. (2008). Sources and effects of ionizing radiation. Report to the General Assembly with scientific annexes (Annex B). New York: UN.

2. Stojanovska, Z., Januseski, J., Bossew, P., Zunic, Z. S., Tollefsen, T., \& Ristova, M. (2011). Seasonal indoor radon concentration in FYR of Macedonia. Radiat. Meas., 46, 602-610. DOI: 10.1016/j.radmeas.2011.04.022.

3. Ćurguz, Z., Stojanovska, Z., Žunić, Z. S., Kolarž, P., Ischikawa, T., Omori, Y., Mishra, R., Sapra, B. K., Vaupotič, J., Ujić, P., \& Bossew, P. (2015). Long-term measurements of radon, thoron and their airborne progeny in 25 schools in Republic of Srpska. J. Environ. Radioact., 148, 163-169. DOI: 10.1016/j. jenvrad.2015.06.026

4. Stojanovska, Z., Boev, B., Žunić, Z. S., Ivanova, K., Ristova, M., Tsenova, M., Ajka, S., Janevik, E., Taleski, V., \& Bossew, P. (2016). Variation of indoor radon concentration and ambient dose equivalent rate in different outdoor and indoor environments. Radiat. Environ. Biophys., 55(2), 171-183. DOI: 10.1007/ s00411-016-0640-y.

5. Janik, M., Tokonami, S., Kovács, T., Kávási, N., Kranrod, C., Sorimachi, A., Takahashi, H., Miyahara, N., \& Ishikawa, T. (2009). International intercomparisons of integrating radon detectors in the NIRS radon chamber. Appl. Radiat. Isot., 67(9), 1691-1696. DOI: 10.1016/j.apradiso.2009.03.006.

6. Clouvas, A., Takoudis, G., Xanthos, S., Potiriadis, C., \& Kolovou, M. (2009). Indoor radon measurements in areas of northern Greece with relatively high indoor radon concentrations. Radiat. Prot. Dosim., 136(2), 127-131. DOI: $10.1093 / \mathrm{rpd} / \mathrm{ncp} 154$. 
7. Vaupotic, J. (2012). Radon in kindergartens and schools - a review. In Z. Li, \& Ch. Feng (Eds.), Handbook of radon: properties applications and health (pp. 477-524). New York: Nova Science Publishers.

8. Vaupotic, J., \& Kobal, I. (2002). Correlation between short-term and long-term radon measurements. Isot. Environ. Health Stud., 38(1), 39-46. DOI: 10.1080/10256010208033308.

9. Ringer, W., Bernreiter, M., Kaineder, H., \& Maringer, F. J. (2004). Radon concentrations during working time vs. total average radon concentrations in Austrian kindergartens and schools. In Proceedings of 11th International Congress of the International Radiation Protection Association, Madrid, Spain, 23-28 May 2004. Downloaded 15 December 2015, from https://www.ipen.br/biblioteca/cd/irpa/2004/ files $/ 5 \mathrm{k} 10$. pdf.

10. Gulan, L. R., Bochicchio, F., Carpentieri, C., Milic, G. A., Stajic, J. M., Krstic, D. Z., Stojanovska, Z. A., Nikezic, D. R., \& Zunic, Z. S. (2013). High annual radon concentration in dwellings and natural radio- activity content in nearby soil in some rural areas of Kosovo and Metohija. Nucl. Technol. Radiat., 28, 60-67. DOI: 10.2298/NTRP1301060G.

11. Al-Jarallah, M. I., Fazal, R., \& Khalid, A. (2008). Comparative study of short- and long-term indoor radon measurements. Radiat. Meas., 43, S471-S474. DOI: 10.1016/j.radmeas.2008.04.053.

12. Vuchkov, D., Ivanova, K., Stojanovska, Z., Kunovska, B., \& Badulin, V. (2013). Radon measurement in schools and kindergartens (Kremikovtsi municipality in Bulgaria). Rom. J. Phys., 58(Suppl.), S328-S335.

13. Barros, N. G., Steck, D. J., \& Field, R. W. (2014). A comparison of winter short-term and annual average radon measurements in basements of a radon-prone region and evaluation of further radon testing indicators. Health Phys., 106(5), 535-544. DOI: 10.1097/ HP.0000000000000004.

14. UNSCEAR. (1988). Sources and effects of ionizing radiation. Report to the General Assembly with scientific annexes (Annex B, par. 105). New York: UN. 